\title{
$N$-Substituted $N^{\prime}$-(2-alkylthio-4-chloro-5-methylbenzenesulfonyl)guanidines - Antibacterial, Cytotoxic Activities and Some Structure-Activity Relationships
}

\author{
BEATA ŻOŁNOWSKA ${ }^{1}$, JAROSŁAW SŁAWIŃSKI ${ }^{1 *}$, ALEKSANDRA GRZONEK ${ }^{1}$, ANNA KĘDZIA $^{2}$, \\ EWA KWAPISZ ${ }^{2}$ and ANNA KAWIAK ${ }^{3,4}$ \\ ${ }^{1}$ Department of Organic Chemistry, Medical University of Gdańsk, Gdańsk, Poland \\ ${ }^{2}$ Department of Oral Microbiology, Medical University of Gdańsk, Gdańsk, Poland \\ ${ }^{3}$ Department of Biotechnology, Intercollegiate Faculty of Biotechnology, \\ University of Gdańsk and Medical University of Gdańsk, Gdańsk, Poland \\ ${ }^{4}$ Department of Human Physiology, Medical University of Gdańsk, Gdańsk, Poland
}

Submitted 29 September 2014, revised 23 December 2014, accepted 16 February 2015

Abstract

\begin{abstract}
A series of $N$-substituted $N^{\prime}$-(2-alkylthio-4-chloro-5-methylbenzenesulfonyl)guanidine derivatives bearing sulfonamide moiety have been screened in vitro for antibacterial activity against isolates from patients with infections of oral cavity, respiratory tract and intestinal tract. The majority of compounds exhibited good antibacterial potency. 1-[4-Chloro-5-methyl-2-(4-trifluoromethylbenzylthio)benzenesulfonyl]3-(3-sulfamoylphenyl)guanidine (13) showed very strong activity, with MIC $\leq 6.2 \mu \mathrm{g} / \mathrm{ml}$ against eleven bacteria strains belonged to Grampositive anaerobes and aerobes. Furthermore, compound 13 exhibited promising activity toward highly resistant microorganisms such as methicillin-resistant Staphylococcus aureus and Enterococcus faecalis. It was found that Parvimonas micra, Finegoldia magna, Peptostreptococcus anaerobius, Propionibacterium acnes showed the highest susceptibility toward the investigated guanidines.
\end{abstract}

Key words: 2-mercaptobenzenesulfonamide, antibacterial activity, polar surface area, sulfonylguanidine, theoretical calculations

Symbiotic relationship of bacteria and humans has beneficial influence on host health by modifying the composition of intestinal microbiota or by direct impact on the host such as modulating the immune response. Unfortunately, many pathogenic bacteria cause various diseases, for example, acute otitis media, sinusitis, pneumonia, bronchitis, sexually transmitted diseases, endocarditis, sepsis, septicemia, as well as infections of skin, soft tissue, surgical wound, urinary tract and gastrointestinal tract (Chu et al., 1996). The use of antibiotics has revolutionized the treatment of these infections, improving health of uncountable number of patients of worldwide (Mishra et al., 2012). However, the use of millions of tonnes of antibiotics over the past 75 years had made almost all pathogenic bacteria resistant to antibiotics commonly used to treat them (Laxminarayan et al., 2013). Antibacterial resistance can be developed through several mechanisms, including alteration by mutations of the antibiotic target, changes in cell permeability or efflux, and horizontal transfer of resistance genes (Rodríguez-Rojas et al., 2013). These bacterial evolutionary processes resulting in reduc- tion of the options of treating bacterial infections in public health, especially in medical interventions such as surgery, transplantation, and chemotherapy. Other consequences of bacterial resistance including illness prolongation, higher rates of mortality in patients and increasing of costs of treatment for resistant infections (Laxminarayan et al., 2013). The most problematic microorganisms that have developed multidrug resistance are methicillin-resistant Staphylococcus aureus (MRSA), penicillin-resistant Streptococcus pneumoniae (PRSP), vancomycin-resistant Enterococcus (VRE) (Eells et al., 2013; Baquero et al., 1991; Steed et al., 2011). A growing number of resistant bacteria impel researchers to develop new antibacterial agents that target the broadest spectrum of bacteria.

Sulfonamides has played important role in treatment of antibacterial infections since over 70 years ego (Connor, 1998). This class of sulfa drugs are mainly used to treat gastrointestinal, upper respiratory tract and urinary tract infections. They are popular due to good tolerance by patients, ease of administration, wide spectrum of antibacterial activity and relatively low costs

\footnotetext{
* Corresponding author: J. Sławiński, Department of Organic Chemistry, Medical University of Gdańsk, Gdańsk, Poland; e-mail: jaroslaw@gumed.edu.pl
} 
(Connor, 1998; Gadad et al., 2000). Sulfonamide derivatives as the structural analogues of $p$-aminobenzoic acid, inhibit the 6-hydroxymethyl-7,8-dihydropteroate synthase and limit of folic acid synthesis in prokaryotes, that is essential to cell growth (Brown, 1962).

Our previous studies concerning synthetic antibacterials (Sławiński et al., 2013) and bioactive properties of sulfonamides prompted us to search the new antimicrobials in our library of $\mathrm{N}$-sulfonamide substituted $N^{\prime}$-(2-alkylthio-4-chloro-5-methylbenzenesulfonyl) guanidines. The guanidine derivatives containing sulfonamide group exhibited anticancer activity and abilities to inhibition of human carbonic anhydrase (hCA) (Żołnowska et al., 2014).

In the present study, the $N$-substituted $N^{\prime}$-(2-alkylthio-4-chloro-5-methylbenzenesulfonyl)guanidines containing sulfonamide moiety 1-29 were investigated for their antibacterial activity against various genera of bacteria isolated from patients with infections of the oral cavity, respiratory tract and intestinal tract. Their activities, as given by the minimal inhibitory concentration (MIC) values are shown in Table I. The guanidine derivatives were synthesized by methods established in our previous paper (Żołnowska et al., 2014) and the structure of each of those compounds (1-29) was displayed in Table I.

Antibacterial susceptibility tests were performed against 28 strains of anaerobic and 28 strains of aerobic bacteria, obtained from Laboratory of Department of Oral Microbiology, Medical University of Gdańsk, Poland. The strains of bacteria were isolated from patients with infections of the oral cavity: gingivitis, periodontal diseases, corrosive ulcers, stomatitis (swabs, paper point), respiratory tract (sputum, swabs), intestinal tract (stool). The samples were quickly $(1 \mathrm{~h})$ sent to the laboratory and inoculated onto agar and incubated under aerobic or anaerobic conditions at $37^{\circ} \mathrm{C}$ for $48 \mathrm{~h}$ (aerobic) and 10-14 days (anaerobic bacteria). The aerobic bacteria were identified according to established procedures. The identification of anaerobic bacteria was based according to physiological, morphological and biochemical reactions (API 20A) (Holdeman et al., 1977; Forbes et al., 2007). Analysis of conversion glucose into $\mathrm{C} 1$ to $\mathrm{C} 6$ fatty acids, lactic, fumaric and succinic acids involved the use of gas chromatography. The ability of the strains to produce fluorescence was observed at a spectrum of ultraviolet radiation (UV). The investigated anaerobes belonged to the following genera: Peptostreptococcus (1 strain), Parvimonas (2), Bifidobacterium (1), Finegoldia (3), Actinomyces (2), Propionibacterium (3), Prevotella (5), Porphyromonas (2), Fusobacterium (4), Bacteroides (4), Parabacteroids (1) and reference strains Bacteroides fragilis ATCC 25285, Bacteroides vulgatus ATCC 8482, Parabacteroides distasonis ATCC 8503, Fusobacterium nucleatum ATCC 25586, Peptostreptococcus anaerobius ATCC 27337, Finegoldia magna ATCC 25285, Propionibacterium acnes ATCC 11827. As a reference substance, metronidazole (Fluka) was applied.

Aerobic bacteria were as follows: Staphylococcus (8), Enterococcus (3), Corynebacterium (2), Klebsiella (2), Acinetobacter (2), Escherichia (2), Citrobacter (2), Pseudomonas (5), Serratia (2) and reference strains S. aureus ATCC 25923, E. faecalis ATCC 29212, Klebsiella pneumoniae ATCC 13883, Acinetobacter baumannii ATCC 19606, Escherichia coli ATCC 25922. Amikacin (Fluka) was used as a reference compound.

The minimal inhibitory concentration (MIC) was defined as the lowest compound concentration which inhibited growth of bacteria. The susceptibility of the anaerobic bacteria was determined by means of the plate dilution technique in Brucella agar supplemented with $5 \%$ sheep blood, menadione and hemin (CLSI, 2007). The compounds were dissolved in $1 \mathrm{ml}$ of DMSO immediately before the experiment. Further dilutions were performed in sterile distilled water. The following concentrations of the compounds were used: 200, 100, $50,25,12.5$, and $6.2 \mu \mathrm{g} / \mathrm{ml}$. The inoculum containing $10^{5} \mathrm{CFU} /$ spot was applied to agar plates with Steers replicator. The inoculated agar plates and compound-free ones were incubated in anaerobic jars for $48 \mathrm{~h}$ at $37^{\circ} \mathrm{C}$ in $10 \% \mathrm{CO}_{2}, 10 \% \mathrm{H}_{2}, 80 \% \mathrm{~N}_{2}$ atmosphere with palladium catalyst and indicator of anaerobiosis.

The susceptibility of the aerobic bacteria was determined by means of agar dilution technique with Mueller-Hinton agar (CLSI, 2006). The compounds were dissolved in $1 \mathrm{ml}$ of DMSO immediately before the experiment. Further dilutions were performed in sterile distilled water. The following concentrations of the derivatives were used: $200,100,50,25,12.5$, and $6.2 \mu \mathrm{g} /$ $\mathrm{ml}$. The inoculum containing $10^{5} \mathrm{CFU} /$ spot was applied to the agar plates with Steers replicator. The inoculated agar plates and compound-free ones were incubated for $24 \mathrm{~h}$ at $37^{\circ} \mathrm{C}$ in aerobic conditions.

P.an. - Peptostreptococcus anaerobius; P.m. - Parvimonas micra; B.b. - Bifidobacterium breve; F.m. - Finegoldia magna; A.o. - Actinomyces odontolyticus; P.ac. - Propionibacterium acnes; P.g. - Propionibacterium granulosum; P.as. - Porphyromonas asaccharolytica; B.v. - Bacteroides vulgatus; F.n. - Fusobacterium nucleatum; S.a. - Staphylococcus aureus MSSA; MRSA - methicillin-resistant Staphylococcus aureus; S.e. - Staphylococcus epidermidis; E.f.-Enterococcus faecalis; C.x. - Corynebacterium xerosis;

\footnotetext{
a the strains that were not sensitive (MIC $\geq 200 \mu \mathrm{g} / \mathrm{ml}$ ) were not presented in table; ${ }^{\mathrm{b}}$ compounds $\mathbf{4}, \mathbf{1 1}, \mathbf{1 5}, \mathbf{1 6}, \mathbf{2 3}, \mathbf{2 5}, \mathbf{2 6}, \mathbf{2 8}$ and $\mathbf{2 9}$ were inactive; ${ }^{c}$ no. of tested strains; ${ }^{\star}$ - MIC $\geq 200 \mu \mathrm{g} / \mathrm{ml}$; NT - not tested; $\mathrm{M}$ - metronidazole; A - amikacin
} 
×

OJ
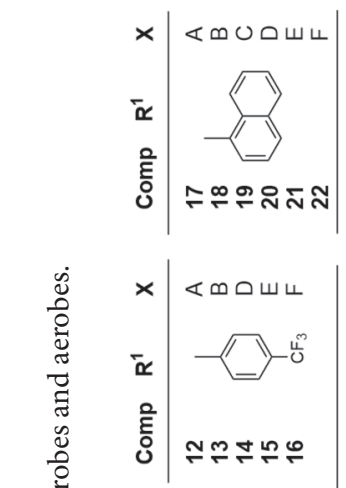

$\times|\varangle \sqcap \cup ロ ய \leftarrow|$

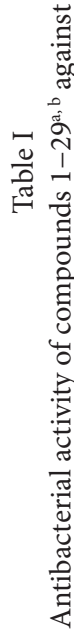

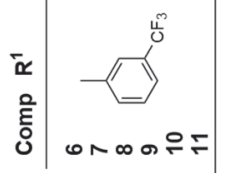

$\times \mid \ll \sqcap \square ய \leftarrow$

$\bar{x}-1$

हे

$-\sin$
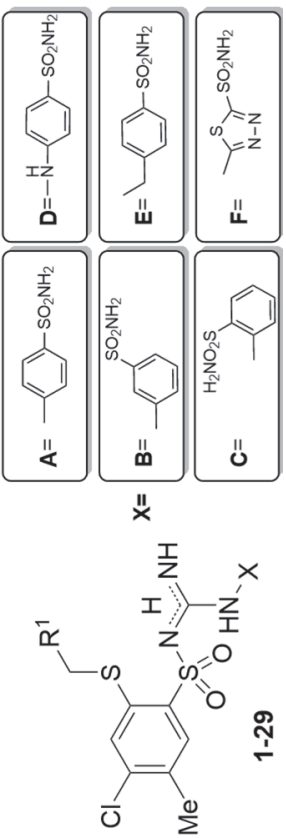

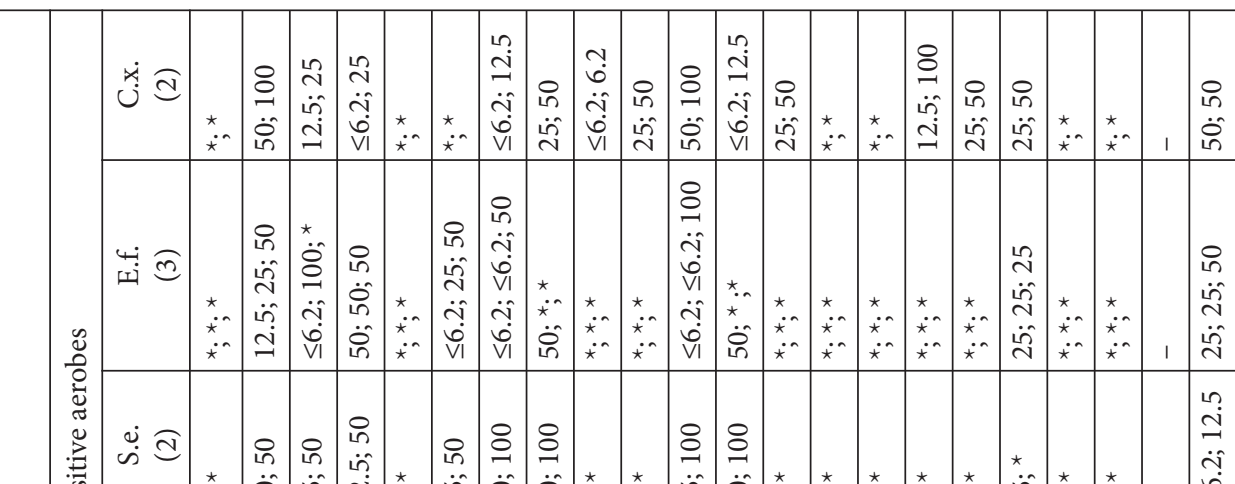

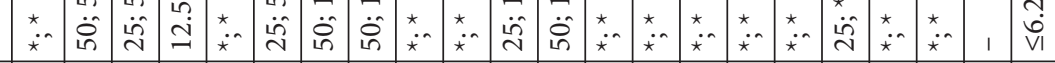

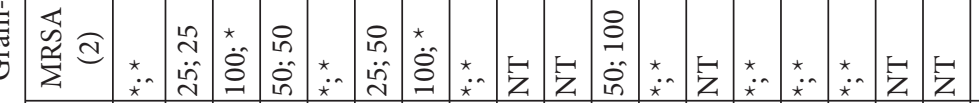

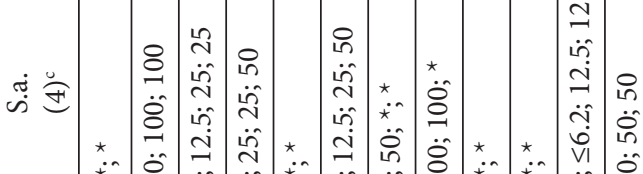

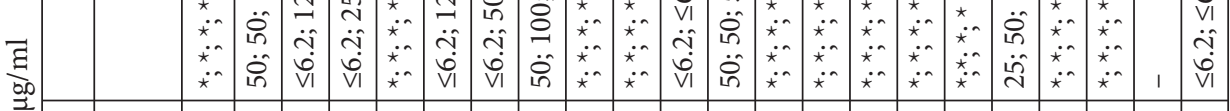

ஜे

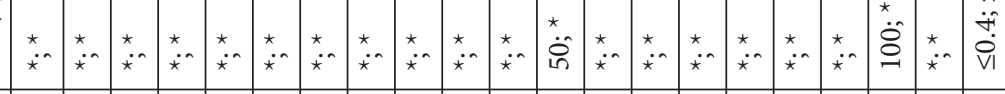

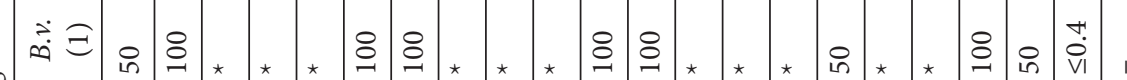

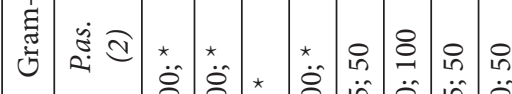

응

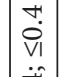

$\sqrt[n]{2}$

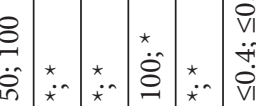

$\operatorname{sic} \widehat{a}$

$\times$

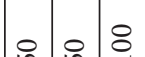

음

$\stackrel{8}{\stackrel{\circ}{N}}$

*

$\stackrel{\star}{\dot{\theta}} \star \dot{8}$

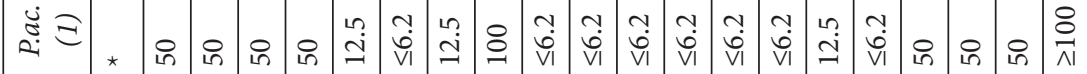

迎

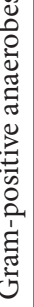

$\widehat{a}$

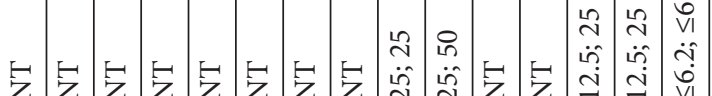

in

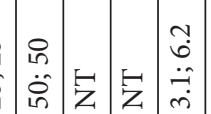

กู่ กู่

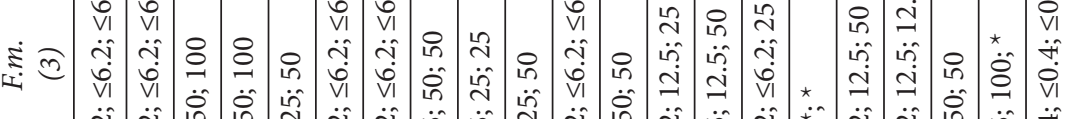

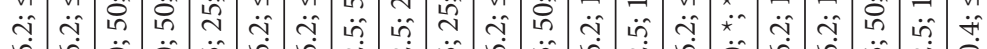

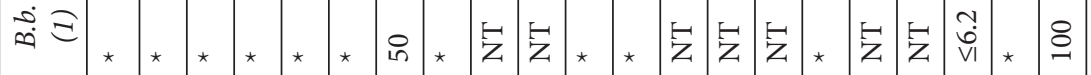

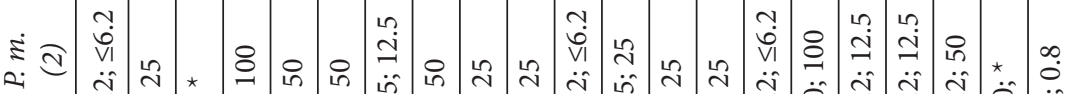

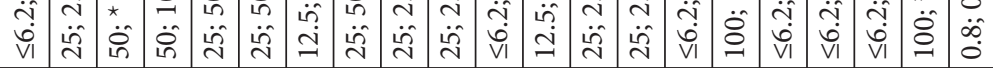

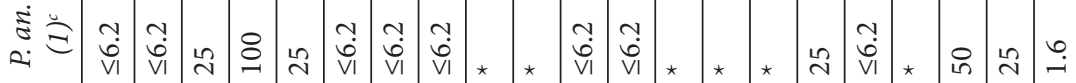

苟 
Generally, tested guanidines showed auspicious antibacterial activity. $N$-Substituted $N^{\prime}$-[4-chloro-5-methyl-2-(3- and 4-trifluoromethylbenzylthio)benzenesulfonyl] as well as $N^{\prime}$ - [4-chloro-5-methyl-2-(naphthalen1-ylmethylthio)benzenesulfonyl]guanidines presented the most active antibacterial agents in anaerobic conditions (Table I). Among them, compounds $8\left(\mathrm{R}^{1}=\right.$ $\left.=3-\mathrm{CF}_{3} \mathrm{Ph}\right)$ and $\mathbf{1 4}\left(\mathrm{R}^{1}=4-\mathrm{CF}_{3} \mathrm{Ph}\right)$ appeared as the promising agents inhibiting the broadest spectrum of anaerobic strains at range of concentration $6.2-100 \mu \mathrm{g} / \mathrm{ml}$. On the other hand, $13\left(\mathrm{R}^{1}=4-\mathrm{CF}_{3} \mathrm{Ph}\right)$ and $19\left(\mathrm{R}^{1}=\right.$ $=1$-naphthyl) showed the very strong antibacterial activity against the largest number of bacterial strains with $\mathrm{MIC} \leq 6.2 \mu \mathrm{g} / \mathrm{ml}$.

The results of our studies indicated that aerobic bacterium were less susceptible toward tested guanidines than anaerobic ones. The most potent compounds 2 , 5 and 13 belonged to $N$-substituted $N^{\prime}$-[4-chloro-5methyl-2-(benzylthio / 3- and 4-trifluoromethylbenzylthio)benzenesulfonyl]guanidines and were active against thirteen aerobic bacterial strains (Table I). It should be pointed out that only $\mathbf{1 3}$ exhibited the highest potential as antibacterial agent with relatively wide range of actions.

Among the screened microorganisms the highest susceptibility against tested guanidines demonstrated P. micra, F. magna, P.acnes and P.anaerobius. It is known that P. micra, F. magna, and P. anaerobius are the most commonly found Gram-positive anaerobic cocci (GPAC) in clinical material (Veloo et al., 2011). Additionally, microbiologists are interested in F. magna because it has one of the highest resistance rates of the GPAC and is capable of producing several virulence factors. The most promising compounds 1 and 13 inhibited simultaneously the growth of three important GPAC with $\mathrm{MIC} \leq 6.2 \mu \mathrm{g} / \mathrm{ml}$. Other relatively sensitive to investigated guanidines strains belonged to P. acnes, which is associated mostly with acne vulgaris but also is found to be the causative agent in discitis, endophthalmitis, or infections of the bones and joints, mouth, eye and central nervous system (Perry and Lambert, 2006; Perry and Lambert, 2011). Surprisingly, methicilinresistant S. aureus (MRSA), one of the most problematic pathogens in hospitals and healthcare facilities were susceptible toward compounds 2, 5, 7 and 13 (MIC; $25-100 \mu \mathrm{g} / \mathrm{ml}$ ), while Enterococcus faecalis, known as multidrug resistant bacteria, were sensitive towards 2, 5, 7-8, 13 and 22 (MIC; 6.2-100 $\mu \mathrm{g} / \mathrm{ml}$ ). From the point of view of resistance of MRSA and enterococci to numerous antibiotics such as the beta-lactams, aminoglycosides, macrolides and lincosamides, the active guanidines seem to be the promising leads in searching for new antibiotics.

It is significant that several tested compounds more effectively inhibited the growth of $B$. breve (two compd), P. acnes (18 compd), P. granulosum (7 compd), MRSA (6 compd), E. faecalis (5 compd), and C. xerosis (11 compd) than reference metronidazole (anaerobes) and amikacin (aerobes) (Table I).

From the obtained results of antibacterial assay some observations concerning the structure-activity relationships (SAR) can be noticed:

1. Antibacterial activity against GPAC depended on structural nature of $\mathrm{R}^{1}$ and $\mathrm{X}$ groups. Comparing the structural properties of $\mathbf{1 3}\left(\mathrm{R}^{1}=4-\mathrm{CF}_{3} \mathrm{Ph}, \mathrm{X}=3\right.$-sulfamoylphenyl) to other compounds with 3-sulfamoylphenyl group as the substituent of guanidine moiety, it should be seen that presence of phenyl $\left(2, \mathrm{R}^{1}=\mathrm{Ph}\right)$ or 4-trifluoromethylphenyl $\left(7, \mathrm{R}^{1}=3-\mathrm{CF}_{3} \mathrm{Ph}\right)$ slightly reduced the activity against only $P$. micra. The presence of 1-naphthyl group as $\mathrm{R}^{1}$ in compound $\mathbf{1 8}$ decreased antibacterial activity (MIC; $12.5-50 \mu \mathrm{g} / \mathrm{ml}$ ) against P. micra and F. magna and made the compound inactive against $P$. anaerobius. In the series of 3-(4-sulfamoylphenyl)guanidines $(\mathrm{X}=\mathrm{A})$ exchanging of phenyl substituent $\left(1, \mathrm{R}^{1}=\mathrm{Ph}, \mathrm{MIC} \leq 6.2 \mu \mathrm{g} / \mathrm{ml}\right)$ into 3 - or 4-trifluoromethylphenyl $(\mathbf{6}, \mathbf{1 2})$ or expanded aromatic fragments $(\mathbf{1 7}, \mathbf{2 7})$ decreased activity against GPAC at different degrees (MIC; 12.5-200 $\mu \mathrm{g} / \mathrm{ml}$ ). For 12 and 17 these modifications caused loss of the activity against P. anaerobius.

2. Compounds 17-22 containing as $\mathrm{R}^{1}$ the 1 -naphthyl group exhibited strong antibacterial activity against bacterium P.acens. As can be seen guanidines with either phenyl, 6-chlorobenzo[ $d][1,3]$ dioxol-5-yl or 2-oxo-1,2-dihydroquinolin-4-yl group showed the significant lower activity (MIC; 50-200 $\mu \mathrm{g} / \mathrm{ml}$ ) then 17-22.

3. Significant bioactivity against the staphylococci was observed for some guanidine derivatives containing phenyl or 3-/4-trifluoromethylphenyl groups as $\mathrm{R}^{1}$. The relatively highest antibacterial activity in this series had compounds with 3-sulfamoylphenyl $(2,7$, 13) and 4-sulfamoylphenylamino $(3,9,14)$ substituents at guanidine fragment. It was also found that for active $5\left(\mathrm{R}^{1}=\mathrm{Ph}, \mathrm{X}=2\right.$-sulfamoyl-1,3,4-thiadiazol-5-yl, MIC; $6.2-50 \mu \mathrm{g} / \mathrm{ml}$ ) exchange of phenyl to 1-naphthyl group decreased antibacterial effect against staphylococci (22, MIC; $25-200 \mu \mathrm{g} / \mathrm{ml}$ ), while substitution with the remaining substituents $\mathrm{R}^{1}$ resulted in loss of bioactivity. The relationship between the structure of guanidine and their antibacterial activity against $E$. faecalis were the same as for staphylococci.

4. Considering the very strong activity of $\mathbf{1 0}$ $\left(\mathrm{R}^{1}=3-\mathrm{CF}_{3} \mathrm{Ph}, \mathrm{X}=\mathrm{E}\right)$ against $C$. xerosis it should be noted that to maintain a good activity of compound, only naphthyl group was acceptable, other modification at substituent $\mathrm{R}^{1}$ caused loss of this effect.

In order to explain some differences in biological activity of investigated guanidines, molecular descriptors, such as polar surface area (PSA), molecular surface 

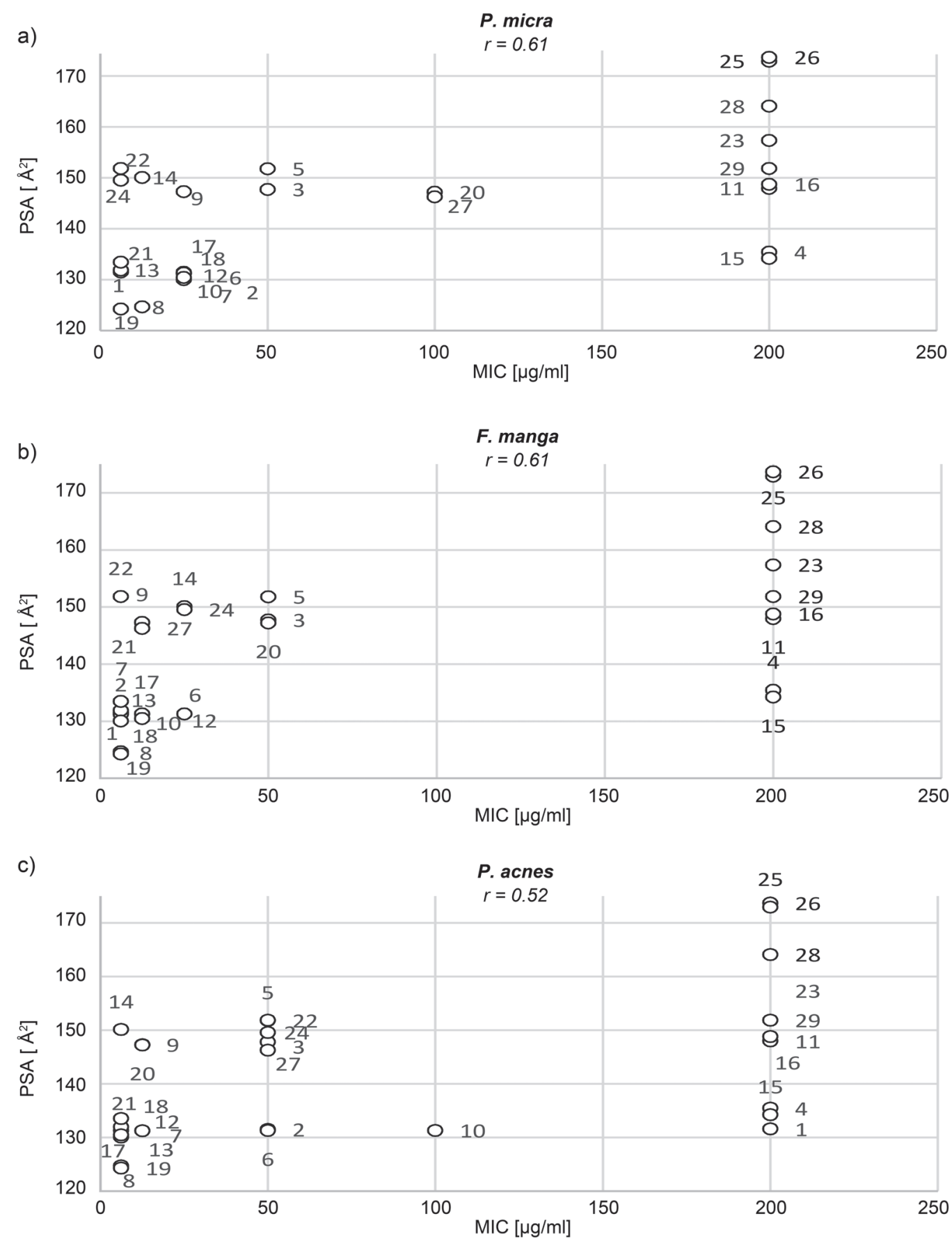

Fig. 1. Plots of antimicrobial activity of compounds 1-29 for P. micra (a), F. magna (b), P. acnes (c) vs calculated PSA. The correlation coefficients $(r)$ ranged from 0.52 to 0.61 .

area, dipole moment, lipophilicity for all compounds were calculated by using SPARTAN '08 software with B3LYP/6-31G* density functional model (SPARTAN '08). Atomic charges of sulphur and nitrogen at sulfonamide groups were also calculated. Statistical analyses of calculated descriptors were performed by STATISTIKA 10. The analysis of structural and electronic parameters has not adjudicated evident influence of these descriptors on biological activity of guanidines. The correlation coefficients $(r$, Fig. 1$)$ showed that for the most susceptible bacteria strains (P. micra, F. magna and P.acnes) the PSA which is defined as the area due to nitrogen and oxygen and any hydrogens attached to nitrogen and oxygen was the best correlated descriptor to the experimental MIC values. The scatter plots (Fig. 1) shows that in the majority compounds with PSA values higher than $151.8 \AA^{2}$ are inactive against P. micra, F. magna and P. acnes. On the other hand, PSA values lower than $140 \AA^{2}$ describe the compounds with high antibacterial activity.

The role of PSA in governing passive diffusion has been widely discussed, as PSA seems to optimally 
Table II

Cytotoxic activities of compounds 2, 5, 7, 8 and 13.

\begin{tabular}{|c|c|c|c|c|c|c|c|}
\hline \multirow{3}{*}{ Compound } & \multicolumn{7}{|c|}{ The human keratinocyte cell line (HaCaT) } \\
\hline & \multicolumn{5}{|c|}{ Cell viability (\%) } & \multirow{2}{*}{$\mathrm{IC}_{50}(\mu \mathrm{M})$} & \multirow{2}{*}{$\mathrm{IC}_{50} \mu \mathrm{g} / \mathrm{ml}$} \\
\hline & $1 \mu \mathrm{M}$ & $10 \mu \mathrm{M}$ & $25 \mu \mathrm{M}$ & $50 \mu \mathrm{M}$ & $100 \mu \mathrm{M}$ & & \\
\hline 2 & $96 \pm 5$ & $100 \pm 1$ & $96 \pm 2$ & $5 \pm 0.5$ & $7 \pm 0.8$ & 35 & 18.4 \\
\hline 5 & $95 \pm 3$ & $98 \pm 1$ & $92 \pm 0.5$ & $100 \pm 0.4$ & $71 \pm 2$ & $>100$ & $>53.0$ \\
\hline 7 & $99 \pm 2$ & $98 \pm 3$ & $100 \pm 2$ & $7 \pm 0.6$ & $8 \pm 1$ & 36 & 21.4 \\
\hline 8 & $97 \pm 3$ & $97 \pm 1$ & $63 \pm 3$ & $6 \pm 0.5$ & $7 \pm 2$ & 30 & 17.8 \\
\hline 13 & $95 \pm 4$ & $92 \pm 0.2$ & $48 \pm 5$ & $7 \pm 2$ & $6 \pm 0.5$ & 24 & 14.2 \\
\hline
\end{tabular}

recapitulate the drug properties that play an important role in membrane penetration. Generally, compounds with PSA $\geq 140 \AA^{2}$ should exhibit poor cell penetration $(\leq 10 \%)$, whereas compounds with PSA $\leq 60 \AA^{2}$ show high absorption ( $\geq 90 \%)$ (Ertl, 2007). Our studies revealed that low antibacterial activity of compounds with high PSA values is due to their limited cellular uptake.

To assess if the effect shown against bacterial cells could be related to a selected toxicity or to a more general toxic effect, we performed assay on the human keratinocytes (HaCaT cell line) to screen the most active compounds $(2,5,7,8$ and 13 , Table II) for their general cytotoxic activity. The HaCaT cell line was cultured in Dulbecco's modified Eagle's medium (DMEM) supplemented with $4500 \mathrm{mg} / \mathrm{l}$ glucose, $10 \%$ fetal bovine serum, $2 \mathrm{mM}$ glutamine, 10000 units penicillin, and $10 \mathrm{mg} / \mathrm{ml}$ streptomycin. Cultures were maintained in a humidified atmosphere containing $5 \% \mathrm{CO}_{2}$ at $37^{\circ} \mathrm{C}$.

Cell viability was determined using the MTT(3(4,5-dimethylthiazol-2-yl)-2,5-diphenyltetrazoliumbromide) assay (Ragab et al., 2013; Morales and Haza, 2013; Suresh et al., 2011). Cells were seeded in 96-well plates at a density of $5 \times 10^{3}$ cells/well and treated for $72 \mathrm{~h}$ with the guanidine derivatives in the concentration range $1-100 \mu \mathrm{M}$. Next, MTT $(0.5 \mathrm{mg} / \mathrm{ml})$ was added directly to the medium and cells were further incubated for $3 \mathrm{~h}$ at $37^{\circ} \mathrm{C}$. The optical density of the formazan solution was measured at $550 \mathrm{~nm}$ with a plate reader (Victor, 1420 multilabel counter). Results are expressed as $\mathrm{IC}_{50}$ values. $\pm \mathrm{SD}$ was calculated from at least three independent experiments.

Experiments indicated that the studied $\mathrm{HaCaT}$ cell line survived even at compound $\mathbf{5}$ concentration of $100 \mu \mathrm{M}(53 \mu \mathrm{g} / \mathrm{ml})$. The $\mathrm{IC}_{50}$ values of compounds 2 , 7,8 and 13 ranged from $24 \mu \mathrm{M}(14.2 \mu \mathrm{g} / \mathrm{ml})$ to $36 \mu \mathrm{M}$ $(21.4 \mu \mathrm{g} / \mathrm{ml})$ and were higher than the lowest MIC values obtained for many bacterial strains (P. anaerobius, P. micra, F. magna, P.acnes, S. aureus, E. faecalis, C. xerosis).

Summarizing, the antibacterial agents found in this paper are useful leads for designing of new effective antibacterial compounds. Results of these preliminary studies need subsequent pharmacokinetic, mechanistic and toxicity evaluations, that will be the aim of new work in the near future.

\section{Literature}

Baquero F., J. Martínez-Beltrán and E. Loza. 1991. A review of antibiotic resistance patterns of Streptococcus pneumoniae in Europe. J. Antimicrob. Chemother. 28 Suppl. C: 31-38.

Brown G.M. 1962. The biosynthesis of folic acid. II. Inhibition by sulphonamides. J. Biol. Chem. 237: 536-540.

Chu D.T.W., J.J. Plattner J.J. and L. Katz. 1996. New directions in antibacterial research. J. Med. Chem. 39: 3853-3874.

Clinical and Laboratory Standards Institute. 2006. Methods of Dilution Antimicrobial Susceptibility Testing for Bacteria That Grow Aerobically; Approved Standard - Seventh Edition. CLSI document M7-A7. Wayne, PA. USA.

Clinical and Laboratory Standards Institute. 2007. Methods for Antimicrobial Susceptibility Testing of Anaerobic Bacteria; Approved Standard - Seventh Edition. CLSI document M11-A7. Clinical and Laboratory Standards Institute, Wayne, PA. USA.

Connor E.E. 1998. Sulfonamide antibiotics. Prim. Care Update Ob Gyns 5: 32-35.

Eells S.J., J.A. McKinnell, A.A. Wang, N.L. Green, P. O'Hara, M.L. Brown and L.G. Miller. 2013. A comparison of clinical outcomes between healthcare-associated infections due to communityassociated methicillin-resistant Staphylococcus aureus strains and healthcare-associated methicillin-resistant $S$. aureus strains. Epidemiol. Infect. 141: 2140-2148.

Ertl P. 2007. Polar Surface Ares, pp. 111-125. In: Mannhold R., Kubinyi H., Folkers G., ed. Molecular drug properties: Measurement and Prediction. Wiley-VCH Verlag GmbH \& Co. KGaA, Weinheim.

Forbes B.A., D.F. Sahn and A.S. Weissfeld. 2007. Bailey and Scott's Diagnostic Microbiology. 12th ed. Mosby Elsevier St. Louis, MO. USA.

Gadad A.K., C.S. Mahajanshetti, S. Nimbalkar and A. Raichurkar. 2000. Synthesis and antibacterial activity of some 5-guanylhydrazone/thiocyanato-6-arylimidazo[2,1-b]-1,3, 4-thiadiazole-2-sulfonamide derivatives. Eur. J. Med. Chem. 35: 853-857.

Holdeman L.V., E.P. Cato and W.E.C. Moore. 1977. Anaerobe Laboratory Manual. VPI 4th ed. Blacksburg, VA. USA.

Laxminarayan R., A. Duse, Ch. Wattal, A.K.M. Zaidi, H.F.L. Wertheim, N. Sumpradit, E. Vlieghe, G.L. Hara, I.M. Gould, H. Goossens and others. 2013. Antibiotic resistance-the need for global solutions. Lancet Infect. Dis. 13: 1057-1098. 
Mishra R.P.N, E. Oviedo-Orta, P. Prachi, R. Rappuoli and F. Bagnoli. 2012. Vaccines and antibiotic resistance. Curr. Opin. Microbiol. 15: 596-602.

Morales P. and A.I. Haza. 2013. Antiproliferative and apoptotic effects of Spanish honeys. Pharmacogn. Mag. 9: 231-237.

Perry A.L. and P.A. Lambert. 2006. Propionibacterium acnes. Lett. Appl. Microbiol. 42: 185-188.

Perry A. and P. Lambert. 2011. Propionibacterium acnes: infection beyond the skin. Expert Rev. AntiInfect. Ther. 9: 1149-1156.

Ragab E.A., A.S. Mohammed, H.S. Abbass and S.I. Kotb. 2013. A new flavan-3-ol dimer from Ficus spragueana leaves and its cytotoxic activity. Pharmacogn. Mag. 9: 144-148.

Rodríguez-Rojas A., J. Rodríguez-Beltrán, A. Couce and J. Blázquez. 2013. Antibiotics and antibiotic resistance: a bitter fight against evolution. Int. J. Med. Microbiol. 303: 293-297.

Sławiński J., B. Żołnowska, D. Pirska, A. Kędzia and E. Kwapisz. 2013. Synthesis and antibacterial activity of novel 4-chloro-2-mercaptobenzenesulfonamide derivatives. J. Enzyme Inhib. Med. Chem. 28: 41-51.

SPARTAN '08 Wavefunction Inc., Irvine, CA 92612, USA.

STATISTIKA 10 software, StatSoft. Inc., Tulsa, OK 74104, USA
Steed M.E., C. Vidaillac, W.E. Rose, P. Winterfield, G.W. Kaatz and M.J. Rybak. 2011. Characterizing vancomycin-resistant Enterococcus strains with various mechanisms of daptomycin resistance developed in an in vitro pharmacokinetic/pharmacodynamic model. Antimicrob. Agents Chemother. 55: 4748-4754.

Suresh H.M., B. Shivakumar, K. Hemalatha, S.S. Heroor, D.S. Hugar and K.R. Rao. 2011. In vitro antiproliferative activity of Annona reticulata roots on human cancer cell lines. Pharmacogn. Res. 3: 9-12.

Veloo A.C., G.W. Welling and J.E. Degener. 2011. Antimicrobial susceptibility of clinically relevant Gram-positive anaerobic cocci collected over a three-year period in the Netherlands. Antimicrob. Agents Chemother. 55: 1199-1203.

Żołnowska B., J. Sławiński, A. Pogorzelska, J. Chojnacki, D. Vullo and C.T. Supuran. 2014. Carbonic anhydrase inhibitors. Synthesis, and molecular structure of novel series $N$-substituted $N^{\prime}$-(2-arylmethylthio-4-chloro-5-methylbenzenesulfonyl)guanidines and their inhibition of human cytosolic isozymes I and II and the transmembrane tumor-associated isozymes IX and XII. Eur. J. Med. Chem. 71: 135-147. 
